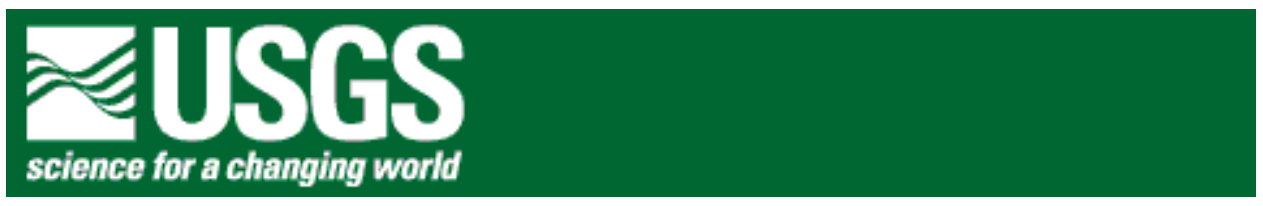

\title{
SEISMIC INSTRUMENTATION OF BUILDINGS
}

By

Mehmet Çelebi ${ }^{1}$

Open-File Report 00-157

This report is preliminary and has not been reviewed for conformity with U.S. Geological Survey editorial standards (or with the North American Stratigraphic Code). Any use of trade, product or firm names is for descriptive purposes only and does not imply endorsement by the $U$. S. Government

April 2000

\footnotetext{
${ }^{1}$ United States Geological Survey (MS977), 345 Middlefield Road, Menlo Park, CA. 94025 ( [Tel: 650-329-5623, Fax: 650-329-5163], [e-mail: celebi@usgs.gov]
} 


\section{TABLE OF CONTENTS}

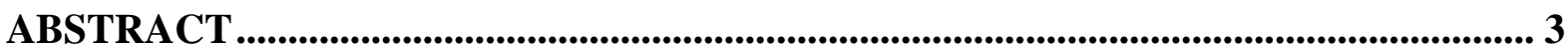

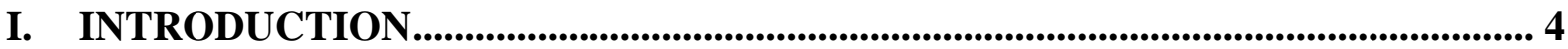

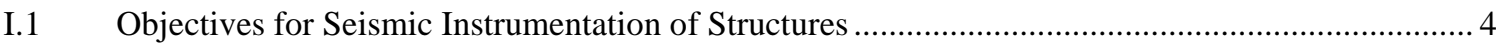

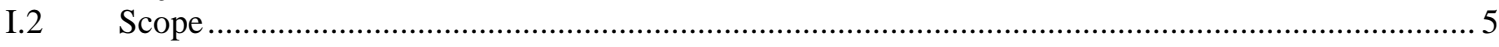

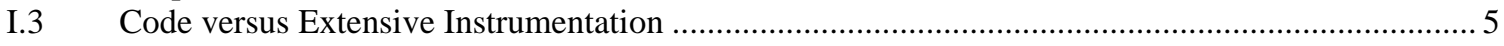

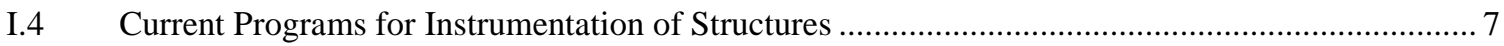

II. STEPS IN INSTRUMENTING A STRUCTURE.......................................................9

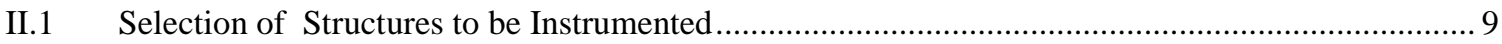

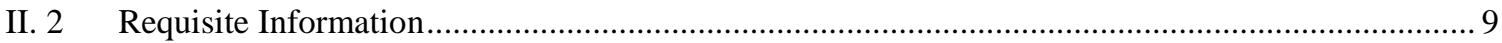

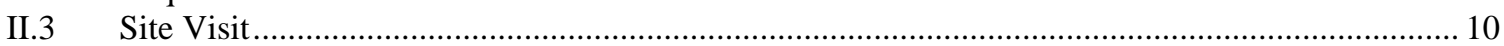

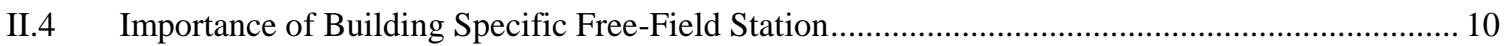

II.5 Tests on Existing Structures to Determine Dynamic Characteristics ............................................ 11

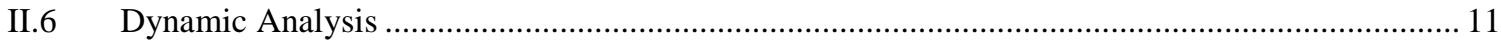

III. SELECTION AND INSTALLATION OF INSTRUMENTS ........................................ 12

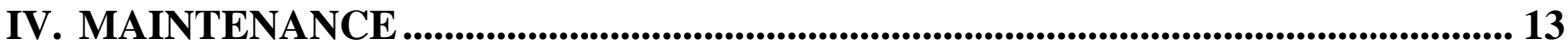

V. DATA RETRIEVAL AND PROCESSING ...................................................................... 14

VI. UTILIZATION OF DATA FROM INSTRUMENTED STRUCTURES.................. 15

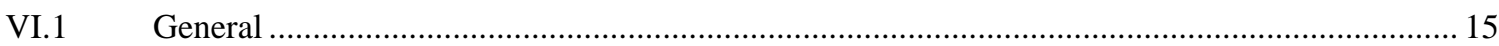

VI.2 A Sample Case: Pacific Park Plaza (Emeryville, Ca.).............................................................. 16

VI.3 Summary of Sample Lessons from Studies of Recorded Structural Responses ......................... 21

VII. COST/BUDGET ISSUES............................................................................................... 25

VIII. CONCLUSIONS .................................................................................................................. 26

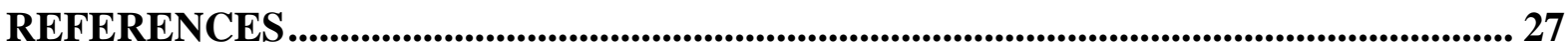

APPENDIX A: DESCRIPTION OF INSTRUMENTS ........................................................... 32

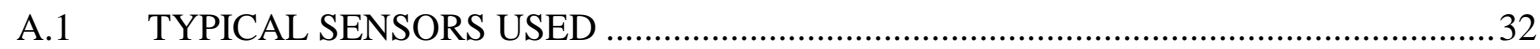

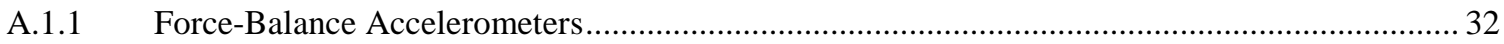

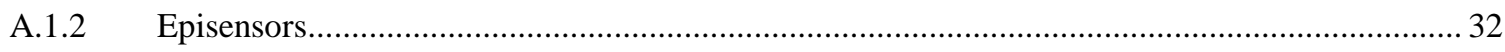

A.2 SUMMARY OF OLDER VERSIONS OF ANALOG RECORDERS ...........................33

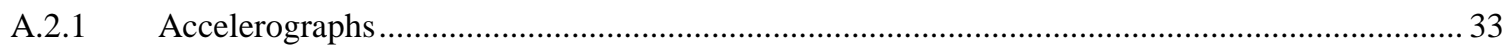

A.2.1.1 Triaxial Strong-Motion Accelerograph (SMA-1):...................................................................... 33

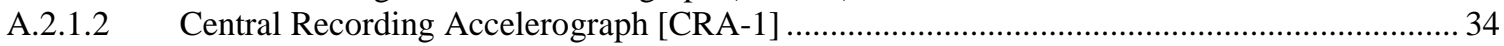

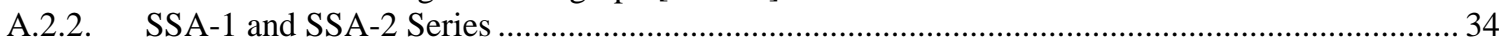

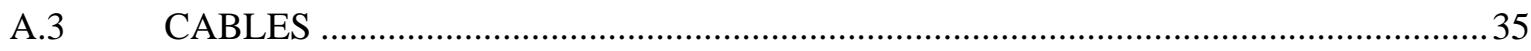

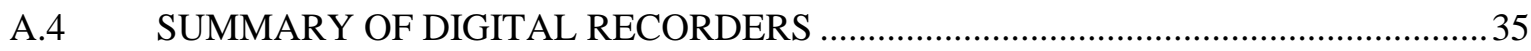

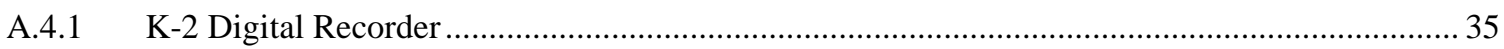

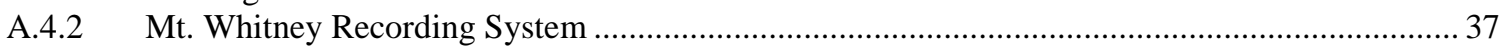




\begin{abstract}
The purpose of this report is to provide information on how and why we deploy seismic instruments in and around building structures.

The recorded response data from buildings and other instrumented structures can be and are being primarily used to facilitate necessary studies to improve building codes and therefore reduce losses of life and property during damaging earthquakes. Other uses of such data can be in emergency response situations in large urban environments.

The report discusses typical instrumentation schemes, existing instrumentation programs, the steps generally followed in instrumenting a structure, selection and type of instruments, installation and maintenance requirements and data retrieval and processing issues. In addition, a summary section on how recorded response data have been utilized is included. The benefits from instrumentation of structural systems are discussed.
\end{abstract}




\section{INTRODUCTION}

There are three main approaches to evaluate seismic behavior and performance of structural systems.

1.Laboratory Testing: Subsystems, components, or (if the facility is large enough) prototypes or large, scaled models of complete systems are tested under static, quasistatic, or dynamic loading. This approach does not necessarily demand a timedependent testing scheme, such as a shaking table or hydraulically powered and electronically controlled loading systems; however, testing of structural systems under controlled simulated environments is desirable. Since the early 1950's such laboratory research has increased both in quantity and quality, with engineering colleges in the United States playing a key role. Laboratory testing has also contributed substantially to our understanding of dynamic soil properties and the interaction phenomenon between the soil and structure.

2. Computerized Analyses: Using special purpose public-domain or private software, structures are analyzed for prescribed loads determined either by code provisions or postulated site-specific ground motions.

3. Natural Laboratory of the Earth: The third main approach to evaluate the behavior and performance of structural systems is to use the natural laboratory of the Earth, by observing and studying the performance (and possibly the damage to structures) following earthquakes. By determining why specific designs lack earthquake resistance and then by using extensive laboratory testing of modified designs, significant progress in improved designs can be achieved. For such design studies a natural laboratory would be a seismically prone area that offers a variety of structural systems; in optimum test areas, strong ground motions as well as moderate-level motions would be experienced frequently. Integral to the "natural laboratory" approach is the advance instrumentation of selected structures so that their responses can be recorded during future earthquakes. Thus, it is essential that integrated arrays of instrumentation be planned and installed to assess thoroughly the relation of ground motion that starts at a source and is transmitted through various soils to a substructure and finally to a superstructure. The direction for seismologists and engineers working together is clear; to develop integrated networks which measure the seismic source, the transmittal of ground motion, and the structural response processes.

\section{I.1 Objectives for Seismic Instrumentation of Structures}

The main objective of seismic instrumentation program for structural systems is to improve our understanding of the behavior and potential for damage of structures under the dynamic loads of earthquakes. As a result of this understanding, design and construction practices can be modified so that future earthquake damage is minimized. 
An instrumentation program should provide enough information to reconstruct the response of the structure in enough detail to compare with the response predicted by mathematical models and those observed in laboratories, the goal being to improve the models. In addition, the data should make it possible to explain the reasons for any damage to the structure. The nearby free-field and ground-level time history should be known in order to quantify the interaction of soil and structure. More specifically, a well-instrumented structure for which a complete set of recordings has been obtained should provide useful information to:

(1) check the appropriateness of the dynamic model (both lumped-mass and finite element) in the elastic range,

(2) determine the importance of nonlinear behavior on the overall and local response of the structure,

(3) follow the spreading nonlinear behavior throughout the structure as the response increases and determine the effect of this nonlinear behavior on the frequency and damping,

(4) correlate the damage with inelastic behavior,

(5) determine the ground-motion parameters that correlate well with building response damage, and

(6) make recommendations eventually to improve seismic codes (Çelebi and others, 1987).

(7) facilitate decisions to retrofit/strengthen the structural system as well as securing the contents within the structures.

\section{I.2 Scope}

The scope of this report is intended to consider issues that are related to instrumentation of structures and a variety of structural instrumentation schemes including those at free-field near structures. Thus, we are concerned mainly with how real structures respond to damaging earthquakes. Ultimately, the data obtained should reveal the performance of the subject structure at a particular site.

\section{I.3 Code versus Extensive Instrumentation}

The most widely used code in the United States, the Uniform Building Code (UBC-1997 and prior editions), recommends, for seismic zones 3 and 4, a minimum of three accelerographs be placed in every building over six stories with an aggregate floor areas of 60,000 square feet or more, and in every building over ten stories regardless of the floor area. The purpose of this requirement by the UBC was to monitor rather than to analyze. UBC-Code type instrumentation is illustrated in Figure 1a.

The UBC-type instrumentation, because it is designed for monitoring, is not necessarily a useful first stage for the instrumentation being discussed. Experiences from past earthquakes show that the UBC minimum guidelines do not ensure sufficient data to perform meaningful model verifications. As an example, three horizontal accelerometers are required to define the horizontal motion of a floor (two translations and torsion). Rojahn and Matthiesen (1977) concluded that the predominant response of a high-rise building can be described by the 
participation of the first four modes of each of the three sets of modes (two translations and torsion); therefore, a minimum of 12 accelerometers would be necessary to record these modes. If vertical motion and rocking are expected to be significant and need to be recorded, at least three vertical accelerometers are required at the basement level. This type of instrumentation scheme is called the ideal extensive instrumentation scheme herein and is illustrated in Figure 1b.

Figures 1c and 1d illustrate typical special purpose instrumentations. Diaphragm effects are best captured by adding sensors at the center of the diaphragm as well as the edges (Figure 1c).

UBC RECOMMENDATION

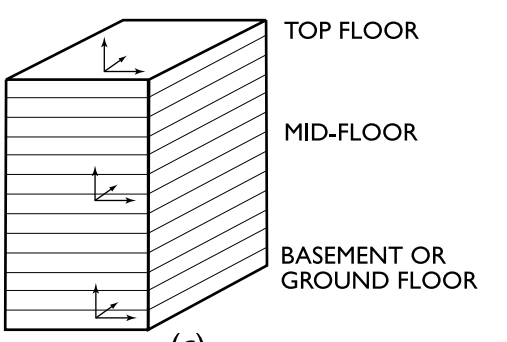

(a)
IDEAL EXTENSIVE INSTRUMENTATION

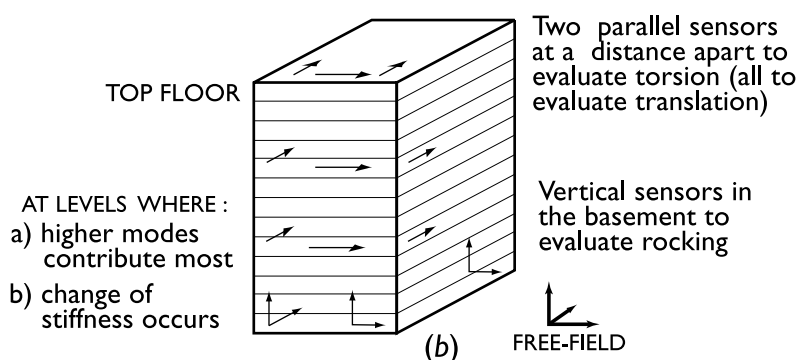

(b) FREE-FIELD

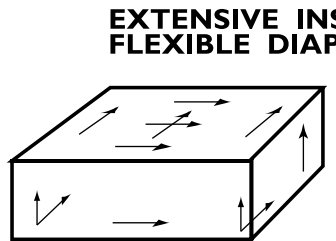

(c)

(d)

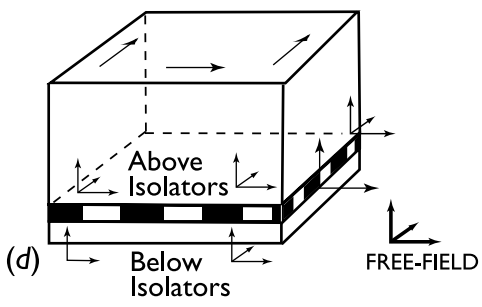

EXTENSIVE INSTRUMENTATION SPECIAL STRUCTURES
BASE-ISOLATED BUILDINGS

Figure 1. Typical Instrumentation Schemes

Performance of base-isolated systems and effectiveness of the isolators are best captured by measuring tri-axial motions at top and bottom of the isolators as well as the rest of the superstructure (Figure 1d).

Furthermore, high-precision record synchronization must be available within a structure if the response time histories are to be used together to reconstruct the overall behavior of the structure. Rojahn and Raggett (1981) provided some additional guidelines for the instrumentation of bridges, and instrumentation of earth dams has been addressed by Fedock (1982).

Within the last decade plus, system identification techniques have made it possible to identify structural characteristics (modal frequencies, modal damping) using recorded responses of 
structures (Ljung, 1987). These methods have evolved into single-input single-output and multi-input multi-output versions that enable construction of modal shapes.

Like the superstructure, the foundation system needs to be instrumented to study its response. This is easily accommodated along the instrumentation scheme of the superstructure. Placing sensors at critical locations of the foundation to capture all its relevant motions will at a minimum facilitate study of its behavior.

However, more information is required to interpret the motion of the foundation substructure relative to the ground on which it rests. Engineers use free-field motions as input motion at the foundation level, or they obtain the motion at foundation level by convoluting the motion through assumed or determined layers of strata to base rock and deconvoluting the motion back to foundation level. To confirm these processes requires downhole instrumentation near or directly beneath a structure. Downhole data are especially scarce, although a few such arrays have been developed outside of the United States. These downhole arrays will serve to yield data on:

(1) the characteristics of ground motion at bedrock at a defined distance from a source and

(2) the amplification of seismic waves in layered strata.

Instrumentation needs of a structure have been addressed by Rojahn and Matthiesen (1977), Hart and Rojahn (1979) and Çelebi and others (1987).

\section{I.4 Current Programs for Instrumentation of Structures}

Programs for instrumentation of structures can be classified into three categories:

1. Federal Programs. The U.S. Geological Survey (USGS) has its own nationwide instrumentation program. In addition, if requested, USGS will coordinate, install, maintain, and process the data acquired from strong-motion arrays and structures instrumented by various Federal agencies, state and local governments and private organizations.

2. State Programs. In California, the State Division of Mines and Geology (CDMG) has the responsibility to develop strong-motion arrays to instrument typical structures within the State of California (Shakal, 1984). Other states (for example, Alaska) have similar programs.

3. Private Institutions. Some private institutions such as International Business Machines (IBM), Kaiser Permanente (Kaiser), Pacific Gas \& Electric Company (San Francisco, CA.) and University of Southern California (USC) have developed their own instrumentation programs.

Through these programs, more than 400 structures are known to be instrumented (National Research Council, 1982). Although these networks, particularly the USGS, CDMG, and USC networks, were designed with full cooperation, maintenance of these instruments and data processing are done by each program separately; therefore, at present there is no national 
coordination of efforts (National Research Council, 1982). Similar concerns were aired during a national strong-motion instrumentation workshop (Iwan, 1981). However, recently, a new organization, Consortium of Organizations for Strong-Motion Observation Systems (COSMOS, 1999) has been incorporated to fill this void. 


\section{STEPS IN INSTRUMENTING A STRUCTURE}

\section{II.1 Selection of Structures to be Instrumented}

In selecting structures for seismic instrumentation, unless other factors are considered and/or specific organizational choices are made a priority, the following general parameters can be followed to rank structures for instrumentation:

1. Structural parameters: the construction material, structural system, geometry, discontinuity, and age,

2. Site-related parameters:

a. Severity-of-shaking factor to be assigned to each structure on the basis of its closeness to one or more of the main faults within the boundaries of the area considered (e.g. for the San Francisco Bay area, the San Andreas, Hayward, and Calaveras faults are considered).

b. Probability of a large earthquake $(\underline{M}=6.5$ or 7 occurring on the fault(s) within the next 30 years was obtained. The purpose of this parameter is to consider the regions where there is strong chance of recording useful data within an approximately useful life of a structure.

c. Expected value of strong shaking at the site, determined as the product of $a$ and $b$.

3. Building usage, functionality, occupancy and relevance to life safety requirements following damaging earthquakes.

4. Other parameters of interest to owners or public officials.

The next step in ranking structures is to assign rational weighting factors for structural parameters and site-related parameters. A ranked list of structures emerges from this effort.

As an example, the USGS, with input from an Instrumentation Advisory Committee for the San Francisco Bay Area, in 1983 developed a recommended list of structures for seismic instrumentation and rank them according to a rational set of parameters and criteria (Çelebi and others, 1984).

Once the particular structure to be instrumented is identified, the engineering staff in turn obtains instrumentation permits for selected structures, gathers information relative to the project including structural plans and design and model information, and directs structural evaluation and if necessary performs ambient response studies.

\section{2 Requisite Information}

Once it is decided to instrument a particular structure and permit is obtained, it is imperative that a series of studies, deductions, and decisions be made. Furthermore, it is important to optimize the instrumentation schemes from the points of view of both cost and required data. This necessitates study of the expected dynamic behavior of the structure. The preliminary studies include the following steps: 
(1) study of available design and analysis information after permission for instrumenting is granted by the owner,

(2) site visit, and

(3) required analytical studies and tests, if feasible and necessary.

In general, the following information, if available, will be required:

(1) relevant blueprints and design calculations,

(2) dynamic analysis (mode shapes and frequencies),

(3) if available, forced-vibration test results, and ambient-vibration test results.

Seldom is all this information available for any structure. In particular, for a structure that is yet to be constructed, blueprints, design calculations and if available, dynamic analyses may be all the information to design its instrumentation scheme so that part of installations of conduits and cables can be feasibly carried out during construction.

The collected set of data is then used as a basis for determining transducer locations that will adequately define the response of the structure during a strong earthquake.

After the sensor locations have been agreed upon by the engineering staff, the installation team, a representative of the owner of the structure, and an electrical contractor is called in to plan placement of the data cable. The installation team works with the contractor during this phase and subsequently calibrates and installs sensors and recording systems. A final step is a complete documentation of each transducer location and orientation, characteristics of total system response, and any peculiarities of the instrumentation or access to required sites. These steps are described in more detail in the following section.

\section{II.3 Site Visit}

A general scheme can be prepared after a study of the blueprints and other available information related to dynamic characteristics. However, the general scheme for locating instruments needs to be confirmed by a site visit (for existing buildings). The structure may present various constraints that affect safe installation and reliable performance of the sensors. The site visit enables the technical personnel to make relevant changes in the prepared schemes.

\section{II.4 Importance of Building Specific Free-Field Station}

If physically feasible, it is advisable to include into the instrumentation scheme, a building specific free-field station. Such a free-field station is usually deployed at a distance greater than 1.5-2 times the height of the nearest/tallest building. This is due to the desire that motions recorded by a free-field station should not be influenced by the shaking of the buildings. As can be expected, in urban areas, this may be a problem due to the density of built facilities. 
In general, free-field and ground-level motions should be known in order to quantify the interaction of soil and structure. However, data recorded at building specific free-field stations can be used to augment data bases used for structural response studies as well as ground motion studies including development of attenuation relationships and quantification of site response transfer functions and characteristics.

\section{II.5 Tests on Existing Structures to Determine Dynamic Characteristics}

Although it is possible to obtain a satisfactory understanding of a structure's expected dynamic behavior by preliminary analytical studies, when feasible and necessary, an ambient-vibration and/or a forced vibration test on an existing structure can be performed to identify mode shapes and frequencies. Ambient vibration tests can be performed efficiently using portable recorders at three to five locations that are expected (from analytical studies or other information) to have maximum amplitudes during the first three to four vibrational modes. Thus, elastic properties of the structure can be determined. If the subject structure experiences nonlinear behavior during a strong shaking, it will be much easier to evaluate the nonlinear behavior once linear behavior is determines before the nonlinear behavior occurs during the strong shaking.

Compared to ambient-vibration test, a forced-vibration test is more difficult to perform. The required equipment (vibration generator with control consoles, weights, recorders, accelerometers, and cables) is heavier, and the test takes longer than the ambient-vibration test. Furthermore, state-of-the-art vibration generators do not necessarily have the capability to excite to resonance all significant modes of all structures (Çelebi and others, 1987).

\section{II.6 Dynamic Analysis}

If a dynamic analysis was not prepared by the designers of a structure or the information is unavailable, then a simplified finite-element model could be developed to obtain the elastic dynamic characteristics. This is performed with any one of the several tested computer programs available (e.g. SAP2000, ANSYS, and STRUDL). 


\section{SELECTION AND INSTALLATION OF INSTRUMENTS}

In selection and defining an instrumentation scheme, an optimum list of hardware is developed after careful consideration of cost and data requirements. Appendix A describes technical capabilities of commercially available sample sensors and recording systems. While developing the instrumentation scheme within the budgetary constraints, it is best to consider the maximum available channels for each recording system. Most recording systems have maximum of 12 or 18 channels of recording capability.

The following general approach is followed to install seismic instruments:

1. After an instrumentation scheme is developed and approximate sensor locations are chosen, USGS engineers and technicians and the owner's representative review the site to determine exact sensor locations and routing of cables and conduits, if required, satisfactory to both parties. This is important from viewpoint of long-term accessibility, potential interference with the occupant's space, placement of data cable runs, and aesthetic requirements of the owner. Figure 2 exhibits a sample schematic showing locations of sensors, routing of cables, location of junction boxes and recording units.

2. Next the USGS technician inspects the entire structural scheme with an electrical contractor who will install the data cable, junction boxes at key locations and terminal boxes (if required) at each sensor site. The modern recording systems may not require terminal boxes (see Appendix A - e.g. Mt. Whitney ${ }^{2}$ ) as they have internal terminals. Actual cabling by the contractor is monitored by the USGS and the owner's representative to be sure the cable is installed as desired and that all building code regulations are followed.

3. The cable-termination box (if necessary) is prepared in the USGS shop and includes data circuits, batteries and battery charges. This box is normally mounted on the wall above the recorder. The recorder location is selected on the basis of security, typically in a telephone or electrical switch room, and in some circumstances is enclosed with separate fencing in an open area.

4. The instrumentation undergoes a preliminary calibration in the strong-motion laboratory and is then installed in the structure with appropriate test procedures including a static tilt sensitivity test for each component and determination of direction of motion for upward trace deflection on the record. For modern digital systems, this information is entered into the recorder data section and is stored in a general database. Other documentation includes precise sensor location, period and damping of each unit, location of cable runs, access information, and circuit diagrams.

\footnotetext{
${ }^{2}$ Quotation of brand names does not constitute endorsement of any particular product.
} 


\section{MAINTENANCE}

It is essential to have periodic and consistent maintenance of instruments in order to have a successful program. Unless maintenance arrangements are made, successful recording of data cannot be accomplished. Therefore, routine maintenance is conducted every 3-12 months if circumstances and experience so allow. This maintenance includes the following:
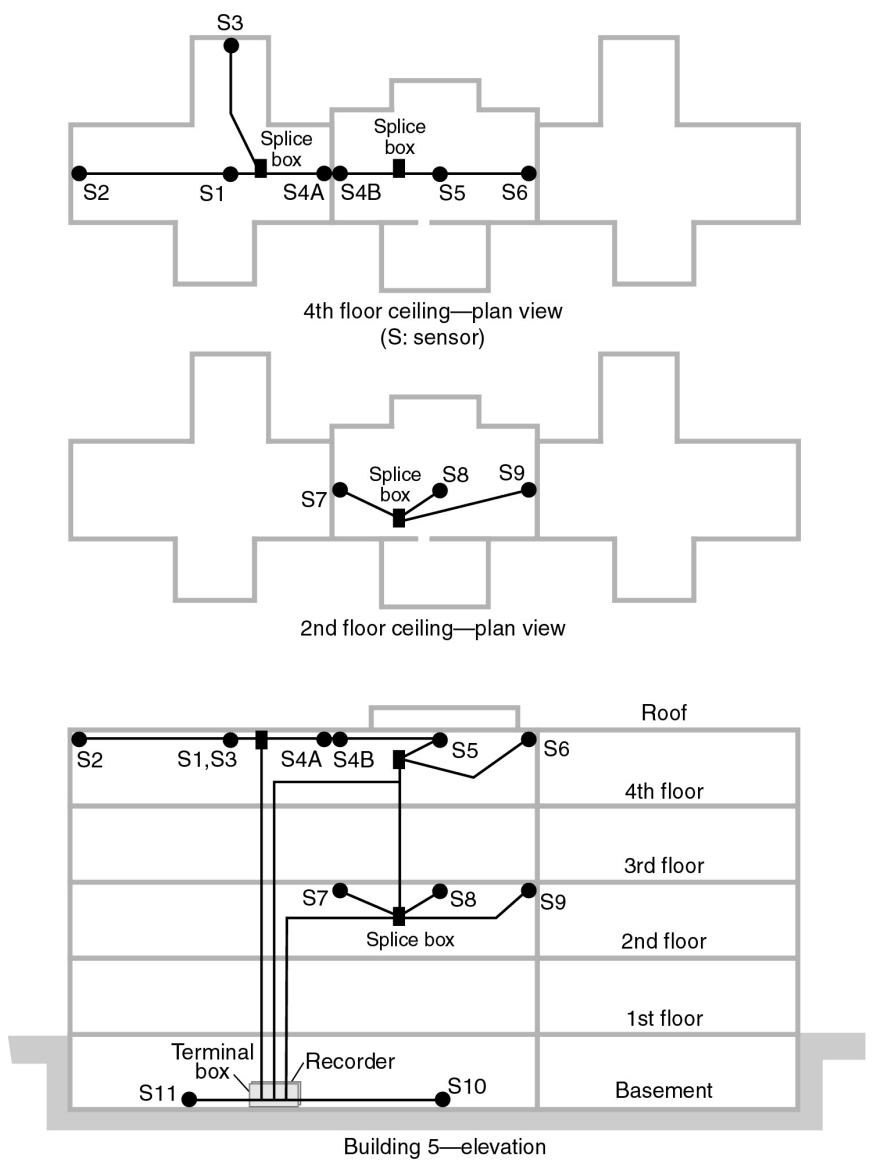

Figure 2. Schematic showing typical deployment of sensors and routing of cables to the recorder.

1. Remote calibration of period and damping.

2. Inspection of battery terminals, load voltage, and charge rate (batteries are replaced every 3 years).

3. Measurement of threshold of triggering system and length of recording cycle.

As a final maintenance procedure, a calibration record is obtained and then examined for the desired characteristics. All inspection procedures are recorded in the permanent station file at the laboratory. 


\section{DATA RETRIEVAL AND PROCESSING}

Modern strong motion instruments now have capabilities to store and transmit digital data through telecommunications links and other media, including the WWW (Appendix A). This communication makes data retrieval easier and faster than with older analog systems, where data were retrieved only by site visits to collect the films and required digitizing by manual or automatic systems. Currently only digital systems are manufactured, so that as the older analog systems are replaced data retrieval and processing will become easier. However, data retrieval by telecommunications has additional hardware costs as well as monthly subscription costs.

1. The data from digital recordings are passed through a correction algorithm that applies a high-frequency filter (typically $50 \mathrm{~Hz}$ ), instrument corrections, if necessary, and decimation to 200 samples per second. A low-cut Butterworth filter (or another appropriate filter) removes all periods longer than a predetermined period from the data. This period is chosen after consideration of the strong-motion duration of the records, any distortion during pre-event signals, displacements calculated at specific sites, and displacements of adjacent film and digital recordings at specific sites. Plots of the corrected acceleration, velocity, and displacements for each channel of recording are prepared.

2. Response spectra are calculated for periods up to about half of the long-period limit. Linear plots of relative-velocity response spectra and the log-log tripartite plots of pseudo-velocity response are prepared.

3. Fourier amplitude spectra, calculated by fast Fourier transform, are presented on linear axes and $\log -\log$ axes.

These sets of processed data are then provided to the user community for their evaluation, assessment of facilities and structures, and research. 


\section{UTILIZATION OF DATA FROM INSTRUMENTED STRUCTURES}

\section{VI.1 General}

Seismic monitoring of structural systems constitutes an integral part of the National Earthquake Hazard Reduction Program in the United States and similar programs in other countries. Recordings of the acceleration response of structures have served the scientific and engineering community well and have been useful in assessing design/analysis procedures, improving code provisions and in correlating the system response with damage. Table 1 summarizes some of the uses for the data from instrumented structures. Unfortunately, only a few damaged structures have been instrumented in advance to perform studies of the initation and progression of damage during strong shaking (e.g. Imperial County Services Building during the 1979 Imperial Valley earthquake, [Rojahn and Mork, 1981]). In the future, instrumentation programs should consider this deficiency. Jennings (1997) summarizes this view as follows: "As more records become available and understood, it seems inevitable that the process of earthquake resistant design will be increasingly, and quite appropriately, based more and more upon records and measured properties of materials, and less and less upon empiricism and qualitative assessments of earthquake performance. This process is well along now in the design of special structures".

The methods used in studying structural response records are quite diverse: (a) mathematical modeling (finite element models varying from crude to very detailed, subjected to timehistory, response spectrum or modal analyses). The procedure requires the blueprints of the structures which may not be readily accessible; (b) system identification techniques: single input/single output or multi input/multi output. In these procedures, the parameters of a model are adjusted for consistency with input and output data (Ljung, 1987); (c) spectral analyses: response spectra, Fourier amplitude spectra, autospectra, $S_{x}$ or $S_{y}$, cross-spectral amplitudes $S_{x y}$, and coherence functions $(\gamma)$ [using the equation : $\gamma_{x y}^{2}(f)=S_{x y}^{2}(f) / S_{x}(f) S_{y}(f)$ ] and associated phase angles (Bendat and Piersol, 1980); and (d) simple procedures based on principles of structural dynamics (e.g. recently Jennings (1997) analyzed data from two buildings within close proximity $(<20 \mathrm{~km})$ to the Northridge epicenter, calculated the base shear from the records as 8 and $17 \%$ of the weights of the buildings, drift ratios as 0.8 and $1.6 \%$ (exceeding code limitations). Jennings (1997) states: "A difference between code design values and measured earthquake responses of this magnitude - approaching a factor of ten - is not a tenable situation."

Until recently, in general, only accelerometers (single, biaxial or triaxial) were used to instrument structures. However, observations of damages during the 1994 Northridge and 1995 Kobe earthquakes, have forced engineers and scientists to focus on performance based

seismic design methods and to find new techniques to control drift and displacements. To verify these developments, sensors directly measuring displacements or relative displacements (transducers, laser devices and GPS units) are now being considered. A recent 
development in using differential GPS measurements for monitoring long-period structures is summarized by Çelebi and others (1999).

\section{VI.2A Sample Case: Pacific Park Plaza (Emeryville, Ca.)}

The 30-story reinforced concrete Pacific Park Plaza Building (PPP) is an equally spaced three-winged, cast-in-place, ductile, moment-resistant framed structure. Constructed in 1983 and instrumented in 1985, it is the tallest reinforced concrete building in northern California. A general view, a plan view, a three-dimensional schematic, and its instrumentation are shown in Figure 3 (Çelebi, 1992, 1996). The building with a 5-ft mat foundation rests on 828 (14-inch-square) prestressed concrete friction piles, each 20-25 $\mathrm{m}$ in length, in a primarily softsoil environment, with an average shear-wave velocity between 250 and $300 \mathrm{~m} / \mathrm{s}$ and a depth of approximately $150 \mathrm{~m}$ to harder soil.
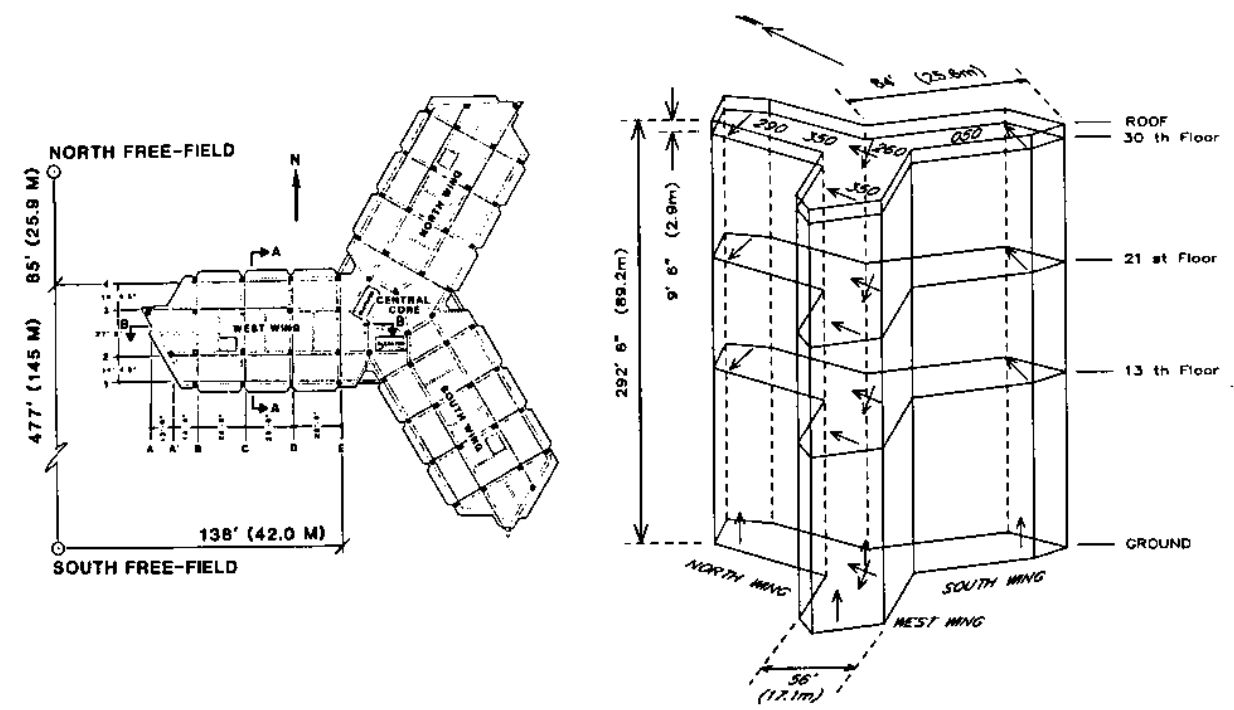

Figure 3. Plan layout and three-dimensional schematic and instrumentation scheme of Pacific Park Plaza (PPP), Emeryville, CA.

The planning for the instrumentation scheme of PPP was achieved after study of the blueprints and after giving careful consideration to the available dynamic analyses and lowamplitude test results. The building was subjected to dynamic analysis and forced-vibration testing by means of a vibration generator (Stephen, written commun., 1984). The important vibrational characteristics (mode shapes and frequencies) are provided in Figure 4 (Stephen, 1984).

From the study of the mode shapes, vibrational data from ground level, the thirteenth and twenty-first floors, and the roof were determined to be most useful. Therefore, instruments placed on each of these levels (Fig. 3) includes two orthogonal sensors at the core as well as an additional sensor at the end of each wing at levels other than the ground level. By obtaining translational accelerations at the core and the wings, it will be possible to determine 
the translational modes of the core and differential translation or torsional vibrations of the wings. Although analytical models of this building indicate that the assumption of flexible foundations does not alter the vibrational characteristics of the building (Stephen, 1984), it is essential to confirm it by means of four vertical sensors (one at the core and one at each wing) at ground level. In addition, a triaxial strong-motion accelerograph is deployed at a free-field site on the south side of the building (SFF or $\left.\mathrm{EMV}^{3,4}\right)$. Thus, a total of 24 sensors (FBA-11) linked to two central recorders (now updated to two digital 12-channel K-2 recording systems) provide a practical instrumentation scheme for this building.

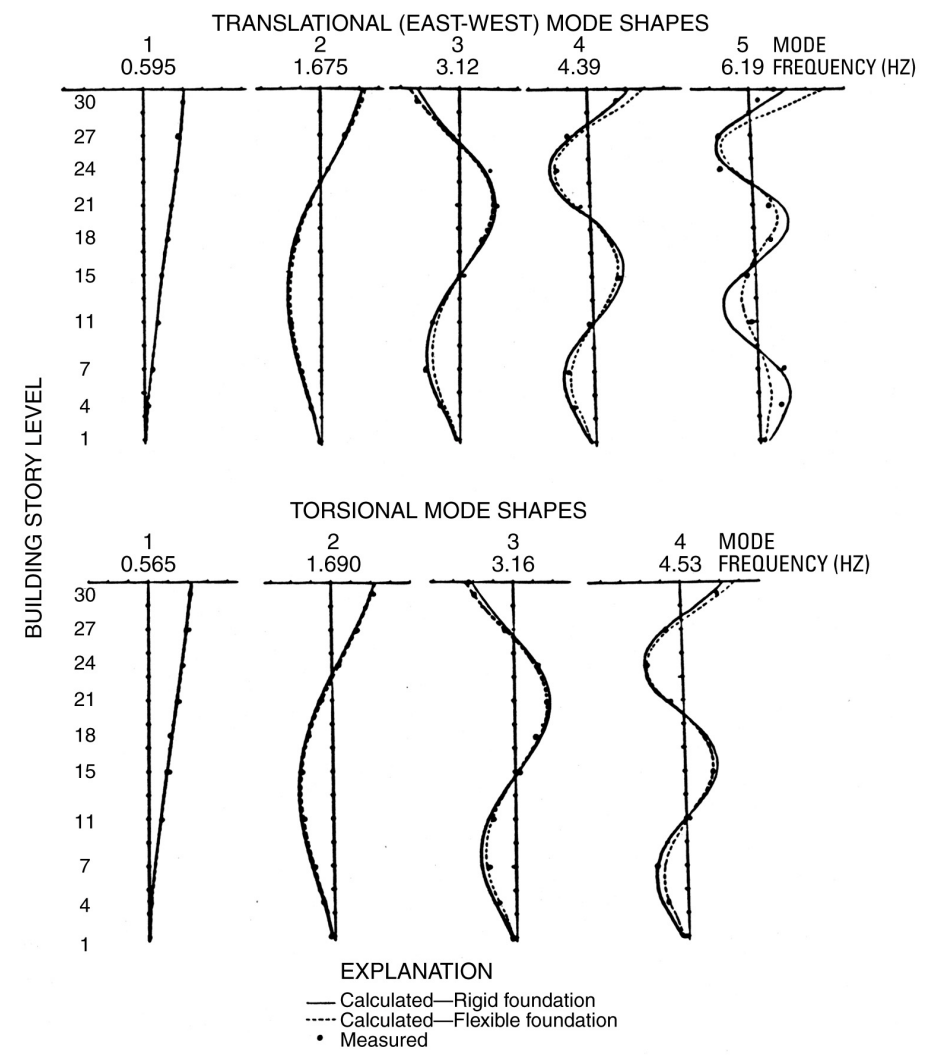

Figure 4. Translational and torsional mode shapes of Pacific Park Plaza (Stephen, 1984)

During the $\mathrm{M}_{\mathrm{s}}=7.1$ Loma Prieta earthquake of October 17, 1989, a complete set of records were obtained from the Pacific Park Plaza (PPP). The building, at $100 \mathrm{~km}$ from the epicenter of the earthquake, had considerably amplified input motions but was not damaged during the earthquake. The east-west components of acceleration recorded at the roof and the ground floor of the structure, at the associated free-field station (SFF in Fig. 3) and, for comparison, the motion at Yerba Buena Island (YBI), the closest rock site with a peak acceleration of $0.06 \mathrm{~g}$, are

\footnotetext{
${ }^{3}$ In most studies, the site of south free-field (SFF) is referred to as the Emeryville site (EMV).

${ }^{3}$ In 1997, the analog recording instruments at Emeryville were upgrade to digital. A downhole accelerograph was

installed at the same location as the surface free-field station, SFF.
} 
shown in Figure 5. The response spectra also shown in Figure 5 clearly demonstrate that the motions at EMV were amplified by as much as five times when compared with YBI. Amplification is also indicated by the amplitude of the peak accelerations $(0.26 \mathrm{~g}$ for EMV and $0.06 g$ for YBI). The differences in peak acceleration at the free-field station $(0.26 g)$ and at the ground floor of the building $(0.21 \mathrm{~g})$ (Fig. 5a) suggest that there was soil-structure interaction (SSI).

In the design of the building, site-specific design response spectra (based on three probabilistic earthquakes based on expected levels of performance) were used: (a) the maximum probable earthquake (50\% probability of being exceeded in 50 years with $5 \%$ damping) anchored at zero period acceleration (ZPA) of $0.32 \mathrm{~g}$, and two maximum credible earthquakes both with 10 $\%$ damping but $10 \%$ probability of being exceeded in (b) 50 years [ZPA of $0.53 \mathrm{~g}$ ] and (c) 100 years [ZPA of $0.63 \mathrm{~g}$ ]. The design response spectra and the spectrum of the EW component of recorded motion at the SFF are shown in Figure 6. The ZPA of the recorded EW acceleration at $\mathrm{SFF}(0.26 \mathrm{~g}$ ) (at $100 \mathrm{~km}$ from the epicenter) is close to that of the postulated maximum probable earthquake $(0.32 \mathrm{~g})$. Furthermore, the spectral accelerations of the EW component of SFF is considerably higher than the maximum probable earthquake for periods $>0.6$ seconds that is, practically for the first three modes of the building. Therefore, one important conclusion derived from the records is that improvements are necessary in establishing site-specific design response spectra to account for realistic shaking at a specific site taking into account expected future closer earthquakes likely to produce larger peak accelerations.
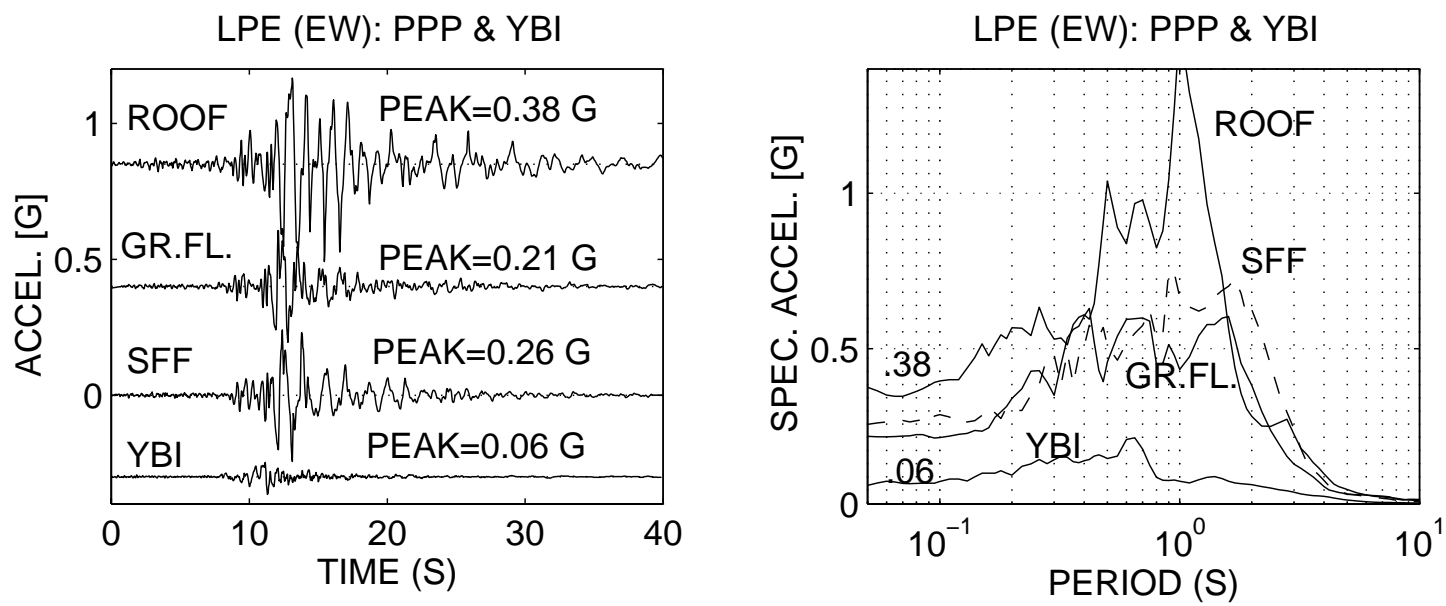

Figure 5. Recorded (EW components) of accelerations and corresponding response spectra at the free-field, ground floor and roof of Pacific Park Plaza (PPP), and at Yerba Buena Island (YBI), at approximately the same distance as PPP, depict the level of amplification. 
Table 1. A Preliminary List of Data Utilization \& Sample References

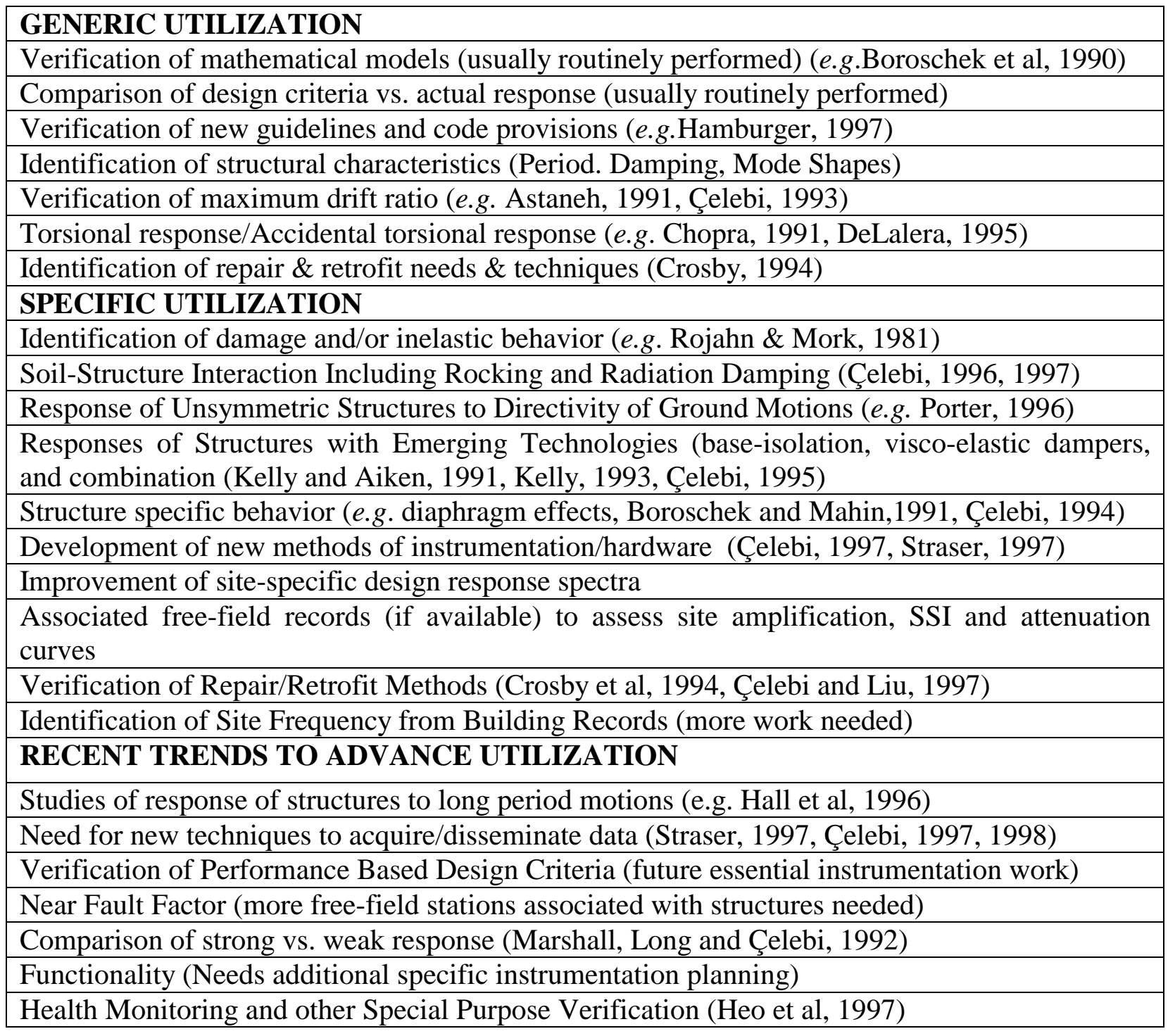

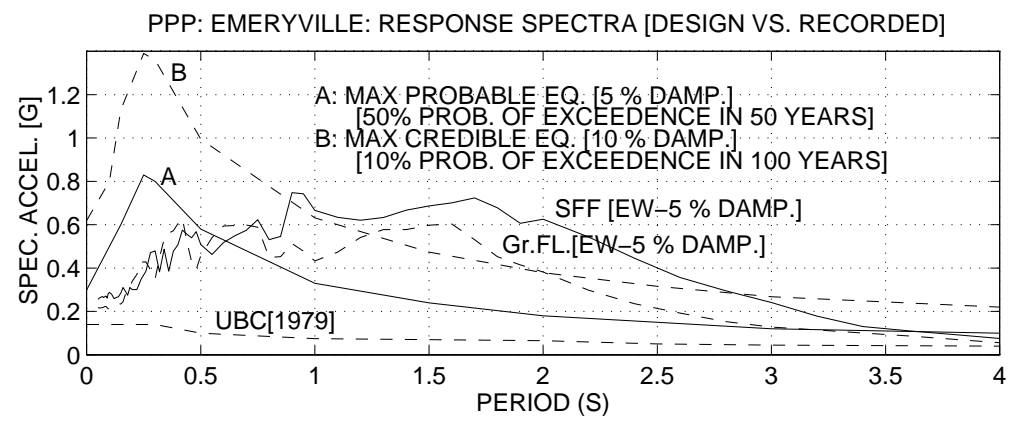

Figure 6. Design response spectra and response spectra of recorded motions at the ground floor and SFF of Pacific Park Plaza. Also shown is the 1979 UBC response spectrum for comparison. 
Using different methods, the building has been studied in detail by Anderson and Bertero (1994), Anderson and others (1991), Kagawa and others (1993), Kagawa and Al-Khatib (1993), Aktan and others (1992), Kambhatla and others (1992) and Çelebi and Safak (1992). All investigators agree that the predominant three response modes of the building and the associated frequencies (periods) are $0.38 \mathrm{~Hz}(2.63 \mathrm{~s}), 0.95 \mathrm{~Hz}(1.05 \mathrm{~s})$, and $1.95 \mathrm{~Hz}(0.51 \mathrm{~s})$. These three modes of the building are torsionally-translationally coupled (Çelebi, 1996) and are depicted in the cross-spectra $\left(S_{x y}\right)$ of the orthogonal records obtained from the roof, ground floor and SFF (the south free-field site) (Figure 7) and the normalized cross-spectra of the orthogonal records (bottom right in Figure 7). The frequency at $0.7 \mathrm{~Hz}(1.43 \mathrm{~s})$ observed in the spectra is this site frequency (Çelebi, 1996).

System identification techniques, when applied to the records of this building, yielded unusually large damping ratios corresponding to the $0.38-\mathrm{Hz}$ first-mode frequency [11.6\% (NS) and 15.5 $\%(\mathrm{EW})$ ] [Table 2] (Çelebi, 1996a). Such unusually high damping ratios attributed to a conventionally designed/constructed building with its large mat foundation in a relatively soft geotechnical environment is due to radiation (or foundation) or material damping. This is one of two cases where large damping percentages implied by the recorded responses of buildings have been attributed to radiation damping; the other case is from the Olive View Hospital in Sylmar, Ca. - data from the Northridge earthquake (Çelebi, 1997).


Figure 7. Cross-spectra of orthogonal accelerations (A350 \& A260) at the roof, ground floor, free-field of PPP. Also shown (bottom right) is the normalized cross-spectrum depicting structural and site frequency peaks. (350 \& 260 depict degrees clockwise from true north). 
Table 2. Summary of dynamic characteristics for Pacific Park Plaza

\begin{tabular}{|c|c|c|c|c|c|c|}
\hline & \multicolumn{3}{|c|}{$\begin{array}{l}\text { Frequencies (Hz) } \\
\text { Mode }\end{array}$} & \multicolumn{3}{|c|}{ Damping (\%) } \\
\hline & \multicolumn{3}{|c|}{ Mode } & \multicolumn{3}{|c|}{ Mode } \\
\hline & 1 & 2 & 3 & 1 & 2 & 3 \\
\hline \multicolumn{7}{|c|}{1989 (LPE) STRONG-MOTION DATA (from Çelebi, 1996) } \\
\hline $\mathrm{N}-\mathrm{S}$ & 0.38 & 0.95 & 1.95 & 11.6 & & \\
\hline E-W & 0.38 & 0.95 & 1.95 & 15.5 & & \\
\hline \multicolumn{7}{|c|}{ MODAL ANALYSES (from Stephen and others, 1985) } \\
\hline N-S & 0.60 & 1.67 & 3.10 & & & \\
\hline E-W & 0.60 & 1.67 & 3.10 & & & \\
\hline TORSION & 0.57 & 1.70 & 3.25 & & & \\
\hline
\end{tabular}

The dynamic characteristics determined from Loma Prieta response records of Pacific Park Plaza as well as those determined from modal analyses (Stephen and others, 1985) are summarized in Table 2. Also, it is noted in Table 2 that although flexibility of the foundation was considered in the 1985 analyses, the structural frequency remained the same as the frequency determined with fixed base assumption. Clearly, the mathematical models developed at that time needed improvements. This conclusion could only be reached because we have recorded on scale motions. Most recent studies indicate that the frequencies from recorded motions can be matched when soil-structure interaction (SSI) is incorporated into the mathematical models (Kagawa and others, 1993; Aktan and others, 1992; Kambhatla and others, 1992). Furthermore, a study of the building for dynamic-pile-group interaction by (Kagawa and Al-Khatib, 1993; Kagawa and others, 1993) indicates that there is significant interaction. Their studies show that computed responses of the building using state-of-the-art techniques for dynamic-pile-group interaction compares well with the recorded responses. On the other hand, Anderson and others (1991) and Anderson and Bertero (1994) concluded that soil-structure interaction was insignificant for Pacific Park Plaza during the earthquake. They compared the design criteria, code requirements, and the elastic and nonlinear dynamic response of this building due to the earthquake using both simplified and detailed analytical models.

\section{VI.3 Summary of Sample Lessons from Studies of Recorded Structural Responses}

Instrumentation of structures as part of hazard reduction programs is very beneficial, as studies of this type will help to better predict the performance of structures in future earthquakes.

(1) Studies of recorded responses of buildings help researches and practicing professionals to better understand the cumulative structural and site characteristics that affect the response of buildings and other structures. Such studies impact mitigation efforts. 
(2) In turn, the behavior that may be expected from buildings during future earthquakes with large input motions (either due to larger magnitude earthquakes or earthquakes at closer distances to the building) can be forecast.

(3) There is a large inventory of buildings within $0-10 \mathrm{~km}$ of the many major faults capable of generating M>7 earthquakes. This is particularly important because, very recently, the Structural Engineers Association of California (SEAOC) issued the 1996 edition of the Recommended Lateral Force Requirements and Commentary which has provisions for increasing the design base shear by 0-100\% depending on the $0-10 \mathrm{~km}$ distance of the building from the fault. This implies that the forecasting of performance of buildings within $0-10 \mathrm{~km}$ of major faults must be done more informatively. This requisite information can be achieved only through acquiring and studying response data from buildings during earthquakes.

(4) There is an acute need to better evaluate structural and site characteristics in developing earthquake-resisting designs of building structures. Studies of recorded responses of structures to date show that designs of buildings with low structural damping, resonation and beating effects caused by closely-coupled translational and torsional modes must be avoided.

(5) As expected in most tall buildings, higher modes are excited. Higher modes play an important role in the response of building structures and therefore must be carefully evaluated to assess their future performances.

(6) Some of the building response data are from tall buildings on soft soils. The motions at the soft-soil sites of some of the important tall buildings are amplified by 3-5 times within the periods of engineering interest when compared with the motions at rock site approximately the same distance away from the epicenter of the earthquake. Responses of tall buildings on soft soils due to motions originating at considerable distances must be accounted for.

(7) Drift ratios calculated from observed data in certain cases exceed code drift limitations for part or all of the structural systems. Assessing the drift exposure of structural systems are ever more important since the design/analyses of buildings are recently being shifted towards a performance based design procedure.

(8) One of the most important aspects of structural behavior that is least understood is the soil-structure interaction (SSI). Such interaction alters the dynamic characteristics of structures and consequently may be beneficial or detrimental to the performance of the structure. In Mexico City (1985), SSI was detrimental. In other cases, it was beneficial. Recorded response data provides much needed information to identify as to when SSI is beneficial and when detrimental. During Northridge, for example, one feature of SSI, radiation damping was found to be helpful in the behavior of the New Olive View Hospital - even though the building experienced resonance. Specific studies are underway to determine improved methods for incorporating SSI into design procedures.

SSI stands to be prominent in the behavior of several instrumented buildings (e.g. Pacific Park Plaza Building [PPP], Santa Clara County Office Building [SCCOB], Transamerica Building [TRA] etc) as assessed from studies of the recorded responses of buildings during the October 17, 1989 Loma-Prieta earthquake $\left(M_{s}=7.1\right)$. Therefore, two specific issues are that (1) identification of beneficial and adverse effects of soil-structure interaction is a necessity, and (2) design offices must 
be informed and trained in consideration of the effect of soil-structure interaction in estimation of fundamental period and damping of a building - as this is not yet the case.

(9) Development of design response spectra deserves more intensive consideration by geotechnical engineers since site effects play an important role in the response of building structures. There are significant discrepancies in the comparison of the response spectra derived from recorded motions with the actual design response spectra. Amplified motions due to soft soil conditions, site-specific resonating frequency content (e.g. basin effects) must be kept in mind in the development of design response spectra.

(10) The propagation direction of surface waves arriving at the buildings affect particularly unsymmetrical buildings or buildings.

(11) Design of basements of tall buildings has been done in the past with input motions at the ground level. Measurements (records) from tall buildings with 2-4 floors of basements indicate that the motions at the basemat are different that that at the ground level. Also the rotations of the basemat are different than the rotations of the sidewalls of the basements. Design considerations for basements therefore need to be reviewed. The implication is that the current practice, which assumes that the inertial forces at the ground level and basemat level to be the same, is not correct. Some suggested changes in design procedures have been made.

(12) Low-amplitude tests have been conducted on five buildings that recorded the Loma Prieta earthquake. Results indicate, as expected, that the first-mode periods extracted from strong motion response records are longer than those associated with the ambient vibration records. Similarly, the percentages of critical damping for the first mode for the ambient data are significantly smaller than those from the strong-motion data. These differences may be caused by several factors including: (a) possible soil-structure interaction which is more pronounced during strong-motion events than during ambient excitations, (and similarly, in buildings with pile-foundations, possible pile-foundation interaction which may not occur during ambient excitation), (b) non-linear behavior of the structure (such as micro-cracking of the concrete at the foundation or superstructure), (c) slip of steel connections, and (d) interaction of structural and non-structural elements. Changes in damping values and fundamental period values commensurate with inferred strong-motion values should be considered to improve design and analyses results.

(13) Specific instrumentation schemes of some of the already instrumented buildings and of those buildings yet to be instrumented must be improved and/or implemented so that the response characteristics expected of that building can be captured (e.g. SSI, pounding, variation of drift due to abrupt changes in stiffness). When applicable, specific buildings should be specially instrumented extensively to better capture their behavior in response to actions such as pounding and SSI.

(14) Because the energy of the ground motions can be azimuthally variable, structures with wings or unsymmetrical structures can be significantly affected by it.

(15) Instrumented structures that have been built or retrofitted with innovative technologies such as base isolated systems indicate which types of base-isolation systems are more effective than others. During the Northridge earthquake, the USC hospital built on rubber bearings performed well but another system did not perform 
as expected. Therefore, instrumentation of structures helps us to identify which innovative emerging isolation technologies perform as expected during strongshaking.

(16) Methods are being developed to identify initiation and propagation of damage by studying the response data from instrumented (and damaged) structures. Unfortunately there were only 2 buildings that were damaged and had seismic instrumentation. This aspect of acquiring information from instrumented structures is gaining importance to develop methods for assessing whether structures are damaged or not.

(17) Response data is providing to be a key to the analyses of few buildings that showed higher shaking at mid-floor levels that their respective top floors. This phenomenon is not yet understood and is being investigated.

(18) Determination of dynamic characteristics of structural systems is important in assessing their vulnerability and in developing procedures to analyze and design future structures. The data recorded from instrumented structures is used to determine structural characteristics. One additional aspect of this is determination of the effect of accidental torsion of symmetric structures. The code provisions that require accidental torsion provisions are now under scrutiny. Following such earthquakes, the formulas in the codes for determination of fundamental periods of structures and design coefficients for assessing the strength requirements have been continuously revised over the years.

(19) Performance of flexible diaphragms of industrial buildings has been improved as a result of studies of recorded motions of such structures.

(20) It has been noted that azimuthal propagation of incoming earthquake motions from different events of different epicentral locations affects the performance of structures that are not symmetrical and/or structures with wings. This issue needs to be studied further to assess how design requirements can be affected by this action.

(21) Studying response records from instrumented structures provides a means to identify the performance problems of the structures and therefore devise and select the best possible retrofit and/or upgrade system. An example of this is the Santa Clara County Office Building in San Jose, California. Records from 3 earthquakes showed that the building resonated and had very low damping. Consequently, the retrofit system selected and implemented is the viscous elastic damper system that increases both the stiffness and damping of the structure. 


\section{COST/BUDGET ISSUES}

The cost of instrumenting a structure in general is based on the number of channels of sensors that will be deployed following decision making process. However, it seems feasible to provide a standardized 12-18 channel instrumentation scheme as most commercially available recording systems have maximum 12 or 18 channels (e.g. K2 and Mt. Whitney, respectively). Experience of a decade and more indicates that the cost can be approximately estimated as follows:

- Each channel of recording system $\sim \$ 1 \mathrm{~K}$

- Each channel of sensor $\sim \$ 1 \mathrm{~K}$

- Installation per channel (labor, cabling etc) $\sim 2 \mathrm{~K}$.

Thus, a 12 -channel system would cost approximately $\$ 48-50 \mathrm{~K}$. This normally will include a triaxial free-field station in the immediate vicinity of the building, if physically possible. Furthermore, the cost can go up depending upon the difficulty with which cables that connect the various sensors at different locations of a building can be pulled to connect the sensors to the recording system.

Instrumentation costs of $\$ 50 \mathrm{~K}$ for a building and its contents is a small investment when compared with the actual worth of a building (and its contents). Naturally, larger and more complex building systems will require more than 12 channels to define its vibrational behavior. In such cases, combinations of 12 and 18 channels are used. 


\section{CONCLUSIONS}

This report presents the current methods and status of instrumenting structures and discusses the benefits derived from instrumenting a structure as well as the extent to which a structure should be instrumented. It also reviews some lessons derived from well-instrumented structures in earthquakes. 


\section{REFERENCES}

Aktan, H., Kagawa, T., Kambhatla, A., and Çelebi, M., 1992, Measured and analytical response of a pile supported building, in Proceedings, Tenth World Conference on Earthquake Engineering: A.A. Balkema, Rotterdam, v. 3, p. 1791-1796.

Anderson, J.C., Miranda, E., and Bertero, V.V., and Kajima Project Research Team, 1991, Evaluation of the seismic performance of a thirty-story RC building: Earthquake Engineering Research Center, University of California, Berkeley, Report: UCB/EERC-91/16, 254 p.

Anderson, J.C., and Bertero, V.V., 1994, Lessons learned from an instrumented high rise building, in Proceedings, Fifth U.S. National Conference on Earthquake Engineering: Earthquake Engineering Research Institute, Oakland, Calif., v. II, p. 651-660.

Astaneh, A., Bonowitz, D., and Chen, C., 1991, Evaluating design provisions and actual performance of a modern high-rise steel structure, in Seminar on Seismological and Engineering Implications of Recent Strong-Motion Data: California Department of Conservation, Division of Mines and Geology, p. 5-1-5-10.

Bendat, J.S., and Piersol, A.G., 1980, Engineering applications of correlation and spectral analysis: John Wiley and Sons, 302 p.

Borcherdt, R.D., Gibbs, J.F., and Lajoie, K.R., 1975, Maximum earthquake intensity predicted for large earthquake: U.S. Geological Survey Miscellaneous Field Studies Map MF-709, scale 1:125,000, 3 sheets.

Boroschek, R. L., Mahin, S. A., and Zeris, C., A., 1990, Seismic response and analytical modeling of three instrumented buildings, PROC., 4th U.S. National Conference on Earthquake Engineering, v.2, pp. 219-228, Palm Springs, Ca., May 20-24.

Boroschek, R. L., and Mahin, S., 1991, An Investigation of the Seismic Response of a Lightly-Damped Torsionally-Coupled Building, University of California, Berkeley, California, Earthquake Engineering Research Center Report 91/18, December, 291 p.

Çelebi, M., and others, 1984, Report on recommended list of structures for seismic instrumentation in the San Francisco Bay Region: U.S. Geological Survey Open-File Report 84-488.

Çelebi, M., Safak, E., Brady, G., Maley, R., and Sotoudeh, V., 1987, Integrated instrumentation plan for assessing the seismic response of structures--a review of the current USGS program, USGS Circular 947.

Çelebi, M., Bongiovanni, G., Safak, E., and Brady, G., 1989, Seismic response of a large-span roof diaphragm: Earthquake Spectra, v. 5, no. 2, p. 337-350. 
Çelebi, M., and Safak, E., 1991, Seismic response of Transamerica Building-I, data and preliminary analysis: Journal of Structural Engineering, v. 117, no. 8, p. 2389-2404.

Çelebi, M. and Safak, E., 1992, Seismic response of Pacific Park Plaza-I, data and preliminary analysis: Journal of Structural Engineering, v. 118, no. 6, p. 1547-1565

Çelebi, M., Phan, L. T., and Marshall, R. D., 1993, Dynamic characteristics of five tall buildings during strong and low-amplitude motions, Journal of Structural Design of Tall Buildings, J. Wiley, v. 2, pp. 1-15.

Çelebi, M., 1993, Seismic response of eccentrically braced tall building, Journal of Structural Engineering, v. 119, no. 4, p. 1188-1205.

Çelebi, M., 1994, Response study of a flexible building using three earthquake records, Structures Congress XII: Proceedings of papers presented at the Structures Congress '94, Atlanta, GA, April 24-28, American Society of Civil Engineers, New York, Vol. 2, 12201225 .

Çelebi, M., 1995, Successful Performance of base-isolated hospital building during the 17 January 1994 Northridge earthquake, Journal of the Structural Design of Tall Buildings, v. 5, pp.95-109.

Çelebi, M., 1996, Comparison of damping in buildings under low-amplitude and strong motions, Journal of Wind Engineering and Industrial Aerodynamics, Elsevier Science, v. 59, pp. 309-323.

Çelebi, M. and Liu, H-P., 1996, Before and After Retrofit - Response of a Building During Ambient and Strong-motions, US National Conference on Wind Eng, The John Hopkins Univ. June 5-7.

Çelebi, M., Presscott, W., Stein, R., Hudnut, K., and Wilson, S., 1997, Application of GPS in Monitoring Tall Buildings in Seismic Areas, 1997a, Abstract, AGU Meeting, San Francisco, Ca., Dec.

Çelebi, M., 1997, Response of Olive View Hospital to Northridge and Whittier earthquakes, American Society of Civil Engineers, Journal of Structural Engineering, April 1997,v.123, no. 4, p. 389-396.

Çelebi, M., 1998, Performance of Building structures - A Summary, in The Loma Prieta, California, Earthquake of October 17, 1989 - Building Structures (M. Çelebi, editor), USGS Prof. Paper 1552-C, pp. c5-c76, January 1998.

Çelebi, M, GPS and/or Strong and Weak Motion Structural Response Measurements - Case Studies, 1998, Structural Engineers World Congress (invited paper), San Francisco, Ca. July 1823, 1998. 
Çelebi, M., Presscott, W., Stein, R., Hudnut, K., Behr, J. and Wilson, S., 1999, GPS Monitoring of Dynamic Behavior of long-Period Structures, 15,1, pp.55-66, Feb. 1999.

Chopra, A., and Goel, R.K., 1991, Evaluation of torsional provisions of seismic codes, J. Struct. Eng. ASCE, 117, 12, 3762-3782.

Converse, A.M., 1984, AGRAM: A series of computer programs for processing digitized strong-motion accelerograms: U.S. Geological Survey Open-File Report 84-562.

Cosmos Newsletter, No: 1, Dec. 1999 (c/e PEER, Bldg. 454, Rm. 121, 1301 South $46^{\text {th }}$ St., Richmond, Ca. 94804).

Crosby, P., Kelly, J., and Singh, J. P., Utilizing visco-elastic dampers in the seismic retrofit of a thirteen-story steel framed building, ASCE Structures Congress XII, Atlanta, Ga., 1994, v. 2, 1286-1291.

De La Llera, J., and Chopra, A., 1995, Understsanding of inelastic seismic behavior of symmetric-plan buildings, Earthquake Engineering and Structural Dynamics, 24, pp. 549572.

Fedock, J.J., 1982, Strong-motion instrumentation of earth-dams: U.S. Geological Survey Open-File Report 82-469.

Hart, G., and Rojahn, C., 1979, A decision-theory methodology for the selection of buildings for strong-motion instrumentation: Earthquake Engineering and Structural Dynamics, v. 7, p. 579-586.

Hall, J. F., Heaton, T. H., Halling, M. W., and Wald, D. J., 1996, Near-source ground motion and its effects on flexible buildings, Earthquake Spectra, v. 11, no. 4, pp. 569-605.

Hamburger, R. O., 1997, FEMA-173 Seismic Rehabilitation Guidelines: The next step Verification, in Proc. SMIP97 Seminar on Utilization of Strong-motion Data, California strong Motion Instrumentation Program, Div. of Mines and Geology, California Dept. of Conservation, Sacramento, Ca., 51-69.

Heo, G., Wang, M. L., and Satpathi, D., 1977, Optimal transducer placement for health monitoring, Soil Dynamics and Earthquake Engineering, 16, pp-496-502.

Hudson, D. E., 1979, Reading and Interpreting Strong-Motion Accelerograms, Earthquake Engineering Research Institute Monographs, Library of Congress No: 79-53973.

Iwan, W.D., ed., 1981, U.S. strong-motion earthquake instrumentation: U.S. National Workshop on Strong-Motion Earthquake Instrumentation: Santa Barbara, Calif., Proceedings, California Institute of Technology, $69 \mathrm{p}$. 
Jennings, P.C., 1997, Use of strong-motion data in earthquake resistant design, in Proc. SMIP97 Seminar on Utilization of Strong-motion Data, California Strong Motion Instrumentation Program, Div. of Mines and Geology, California Dept. of Conservation, Sacramento, Ca., 1-8.

Kagawa, T., Aktan, H., and Çelebi, M., 1993, Evaluation of soil and structure model using measured building response during the Loma Prieta earthquake: Department of Civil and Environmental Engineering, Wayne State University, Detroit, Michigan, 169 p.

Kagawa, T., and Al-Khatib, M.A., 1993, Earthquake response of 30-story building during the Loma Prieta earthquake, in Third International Conference on Case Histories in Geotechnical Engineering, June 1-4, University of Missouri-Rolla, v. I: p. 547-553.

Kambhatla, A., Aktan, H.M., Kagawa, T., and Çelebi, M., 1992, Verification of simple soilpile foundation-structure models, in Structures Congress '92: American Society of Civil Engineers, New York, p. 721- 724.

Kelly, J., 1993, Seismic isolation, passive energy dissipation and active control, PROC. ATC 17-1 Seminar on State of the Art and State of the Practice of Base Isolation, vol. 1, 9-22.

Kelly, J.M., Aiken, I.D., and Clark, P.W., 1991, Response of base-isolated structures in recent California earthquakes, in Seminar on Seismological and Engineering Implications of Recent Strong-Motion Data, Preprints: California Division of Mines and Geology, Strong Motion Instrumentation Program, p. 12-1--12-10.

Lin, B. C., and Papageorgiou, A. S., Demonstration of torsional coupling caused by closely spaced periods---1984 Morgan Hill Earthquake Response of the Santa Clara County Building, Earthquake Spectra, 1989, vol. 5, No. 3, pp. 539--556.

Lindh A.G., 1983, Preliminary assessment of long-term probabilities for large earthquakes along selected fault segments of the San Andreas fault system in California: U.S. Geological Survey Open-File Report 83-63.

Ljung, L., 1987, System identification -- Theory for the User: Prentice-Hall, 519 p.

National Research Council, 1982, Earthquake engineering research--1982: Overview and recommendations: Washington, D.C., National Research Council.

Marshall, R. D., Phan, L. T., and Çelebi, M., 1992, Measurement of structural response characteristics of full-scale buildings: Comparison of results from strong-motion and ambient vibration records, NISTIR REPORT 4884, National Institute of Standards and Technology, Gaithersburg, Maryland.

Porter, L.D., 1996, The influence of earthquake azimuth on structural response due to strong ground shaking, in Eleventh World Conference on Earthquake Engineering, Acapulco, Mexico (June), (No. 1623): Elsevier Science Ltd. (CD-ROM). 
Rojahn, C., and Matthiesen, R.B., 1977, Earthquake response and instrumentation of buildings: Journal of the Technical Councils, American Society of Civil Engineers, v. 103, no. TCI, Proceedings Paper 13393, p. 1-12.

Rojahn, C., and Mork, P.N., 1981, An analysis of strong-motion data from a severely damaged structure, the Imperial County Services Building, El Centro, California: U.S. Geological Survey Open-File Report 81-194.

Rojahn, C., and Raggett, R.D., 1981, Guidelines for strong-motion instrumentation of highway bridges: Federal Highway Administration Report FHWA/RD-82/016.

Rojahn, C., Ragsdale, S.T., Raggett, J.D., and Gates, J.H., 1981, Main-shock strong-motion records from the Meloland Road-Interstate Highway 8 overcrossing: U.S. Geological Survey Open-File Report 81-194.

Rojahn, C., and Mork, P.N., 1981, An analysis of strong-motion data from a severely damaged structure, the Imperial County Services Building, El Centro, California: U.S. Geological Survey Open-File Report 81-194.

Safak, E., and Çelebi, M., 1991, Seismic response of Transamerica Building; - II, System identification and preliminary analysis: Journal of Structural Engineering, v. 117, no. 8, p. 2405-2425.

Safak, E., and Çelebi, M., 1992, Recorded seismic response of Pacific Park Plaza: - II, System identification: Journal of Structural Engineering, v. 18, no. 6, p. 1566-1589

Shakal, A.F., 1984, The California strong-motion instrumentation program; Status and goals: Earthquake Engineering Research Institute Seminar Proceedings, Pasadena, Calif.

Stephen, R.M., Hollings, J.P., and Bouwkamp, J.G., 1973, Dynamic behavior of multistory pyramid-shaped building: Berkeley, Earthquake Engineering Research Center Report EERC 73-17, $97 \mathrm{p}$.

Straser, E., 1997, Toward wireless, modular monitoring systems for civil structures, in the John A. Blume Earthquake Engineering Center Newsletter, Issue No. 2.

Uniform Building Code, International Conference of Building Officials, Whittier, CA, 1970, 1976, 1979, 1982, 1985, 1988, 1991, 1994, 1997 editions. 


\section{APPENDIX A: DESCRIPTION OF INSTRUMENTS}

\section{A.1 TYPICAL SENSORS USED}

\section{A.1.1 Force-Balance Accelerometers}

Sensors usually installed in the free-field and structures are $50-\mathrm{Hz}, 0.7$ critically damped Kinemetrics $^{5}$ force-balance accelerometer models FBA-11, and FBA-13 (respectively uniaxial, and triaxial transducers). Biaxial versions are either ordered specially or mounted on a plate by customers. For special projects where triaxial motions below the ground surface needs to be recorded, tri-axial downhole accelerometers are used. Figure A-1 shows uniaxial, triaxial and downhole accelerometer used. The accelerometers are bolted to the building frame or floor, and sensed data are transmitted to the central recording location by shielded cable.
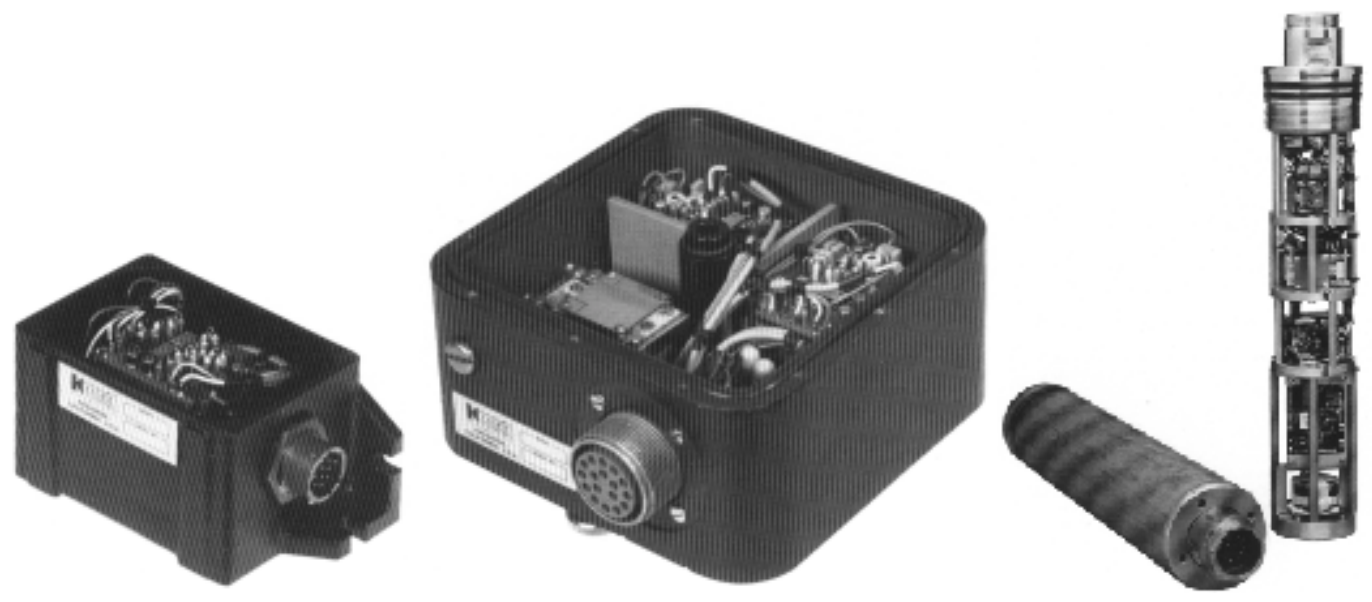

Figure A-1 (from left to right), FBA-11 (uniaxial), FBA-13 (triaxial) and FBA-13DH (downhole)

\section{A.1.2 Episensors}

The latest version of triaxial accelerometer is the Episensor (Figure A-2). Episensor force balance accelerometers are also available in uniaxial (the FBA ES-U) and borehole (the FBA ES-SB shallow and FBA ES-DH deep) packages. The triaxial unit consists of three forcebalance accelerometer modules mounted orthogonally in one package. Recording ranges of \pm 0.25 to $\pm 4 \mathrm{~g}$ are user selectable. The recording bandwidth ranges from DC to $200 \mathrm{~Hz}$. These sensors also have four types of outputs that can be field-selected by the user: $\pm 2.5 \mathrm{~V}$ single-

\footnotetext{
${ }^{5}$ Commercial names cited in this report is for demonstration only and does not constitute endorsement of the product. User should investigate all available products.
} 
ended output for use with traditional Kinemetrics earthquake recording instruments; $\pm 10 \mathrm{~V}$ single-ended or $\pm 20 \mathrm{~V}$ differential output for use with Kinemetrics new Everest 24-bit digital recorder and other 24-bit digital recorders currently on the market.

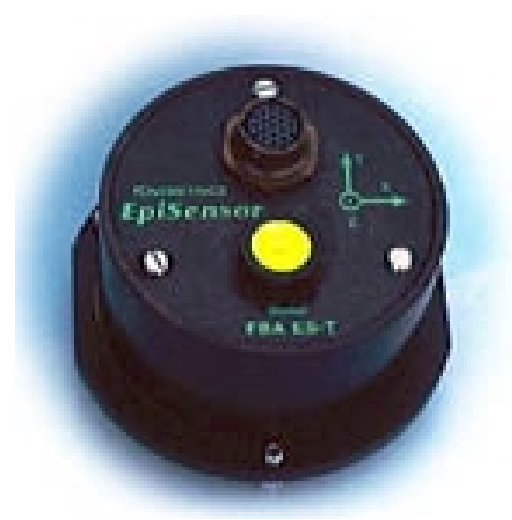

Figure A-2. Triaxial Episensor (13.3 cm diameter, $6.2 \mathrm{~cm}$ height)

\section{A.2 SUMMARY OF OLDER VERSIONS OF ANALOG RECORDERS}

\section{A.2.1 Accelerographs}

It can be stated that tri-axial accelerographs, whether analog or digital, are the most widely used instruments by many national and international organizations to record ground motion as well as structural response. This is because they are versatile enough to be deployed on ground as well as at different locations of structures. That is why perhaps the code-writers (UBC) adopted the tri-axial instruments as the code-requirement. A triaxial accelerograph contains the tri-axial accelerometers within the unit that also houses the recording components. Therefore, it is capable of recording triaxial motions (two orthogonal horizontal components and 1 vertical) at a point on a surface (free-field or structure).

The different types of accelerographs used are:

\section{A.2.1.1Triaxial Strong-Motion Accelerograph (SMA-1):}

Triaxial self-contained accelerographs are often needed and deployed in conjunction with the remote-sensor system either to record free-field ground motions or to supplement the structural instrumentation when more than 12 channels are required.

Although deployment of digital units in Japan, Taiwan and the United States is progressing speedily, Kinemetrics Model SMA-1 is the most widely deployed triaxial, self-contained, analog unit at the present (Figure A-3). This instrument records data optically onto 70-mm photographic film from $25-\mathrm{Hz}$ flexure-type accelerometers. The SMA-1 has the same trigger system, recording capability, and real time options as described for the CRA-1 below. 
However, with new digital units that are competitively priced, SMA-1 models are no longer manufactured and the existing inventory is slowly being replaced by digital units. In fact, the manufacturer is now offering kits to convert analog SMA-1 units to digitally record. Because, in the future, the analog units will not be manufactured and used, detailed descriptions are not provided herein but are available elsewhere (Hudson, 1979).
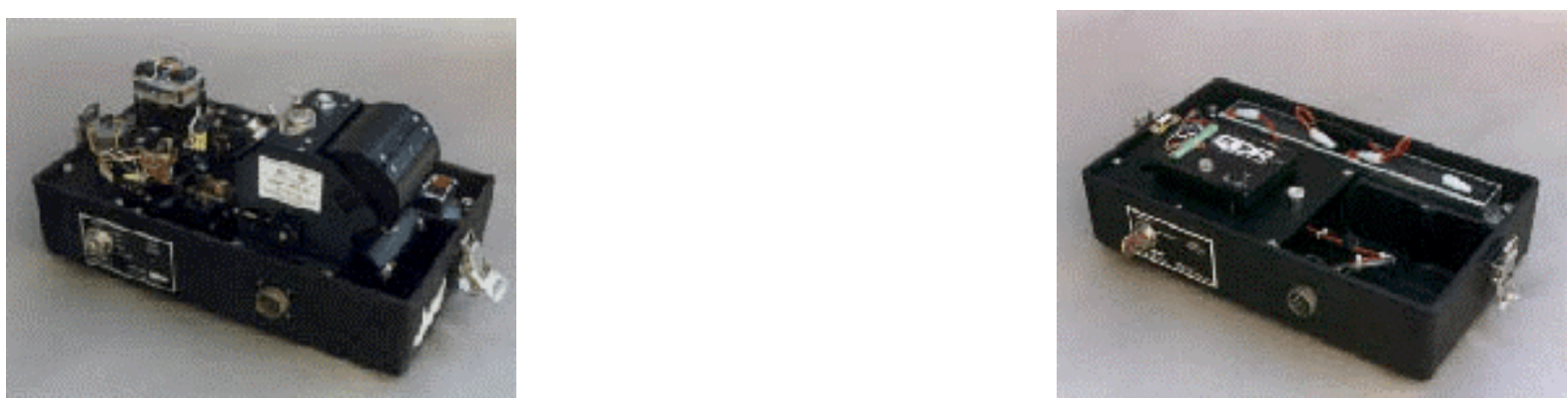

Figure A-3 shows a picture of an SMA-1 and the SMA-1 after digital conversion

\section{A.2.1.2Central Recording Accelerograph [CRA-1]}

Central Recording Accelerograph (CRA) is a 12-channel, analog recording system that records photographically on a single 7 in film. This analog recorder has been usually used for structural-response studies. It can be modified to have a $13^{\text {th }}$ channel. In this system, incoming signals are directly transmitted to $150-\mathrm{Hz}$ galvanometers, which in turn deflect a light beam across the moving film strip. The instrument, triggered by a vertical starter with as nominal threshold of $0.01 \mathrm{~g}$ between 1 and $10 \mathrm{~Hz}$, has a total recording time of 25 minutes. The recording continues to operate for approximately 20 seconds (shop adjustable after the last occurrence of vertical ground motion exceeding the triggering threshold, in order to record the earthquake fully. An internal clock impresses half-second time marks on the edge of the film. A feature by the USGS, puts real time on the opposite edge of the film from an internal time-code generator or by using a WWVB radio code signal. In the latter case the instrument must operate for a minimum of 60 seconds in order to accommodate the entire WWVB code. Float-charged batteries located in a nearby battery box supply power. A rotary key switch provides for periodic testing of natural frequency and damping of the remotely located sensors.

The sensors are connected externally to the CRA unit via a junction box. It is mainly used for structural instrumentation. As with SMA-1, the manufacturer is no longer supplying these units and therefore is not further deliberated herein.

\section{A.2.2.SSA-1 and SSA-2 Series}

These earlier version, 12-bit, solid-state, digital accelerographs record motions at 100-200 samples per second per channel. Newer, 18-24 bit versions of digital systems are now being competitively priced. These earlier versions are no longer being manufactured. 


\section{A.3 CABLES}

When hooking up accelerometers to Altus instruments (K-2 or Mt. Whitney) maximum 6 accelerometers can be hooked up with one cable. It is preferable to hook up 3 accelerometers on one, 6-pair 18-gage cable (Belden part \# 9774 or the equivalent) or to hook up 6 accelerometers to one, 9-pair 18-gage cable (Belden part \# 9775 or the equivalent). One pair is needed for each accelerometer and 3 pairs are used for power and commands to each accelerometer. Up to 6 accelerometers can share the power and command wires. In other words, you need at least one 4 pair cable for one accelerometer on up to one 9 pair cable for 6 accelerometers.

There should be a junction box at each location where the main cable breaks out to pick up more accelerometers. The junction box should be sized according to the number and size of the cables which will be connected in and, or passing through it. The individual accelerometers may be attached to the main cable using insulated Butt Splices such as Panduit part \# BSN18. Wherever the main cable has a break in it, it should be spliced using a tubular, double screw barrier strip with wire protector of the appropriate size (Buchanan part numbers TSB23012DS, TSB5001231DS, and TSB100012DS).

The recorder should be located such that it is the shortest possible run to an outside wall in order to facilitate the installation of 25 meter Bullet GPS antenna. The internal GPS option can be used if you can locate the recorder within 25 meters of the antenna. If this is not possible, then the external GPS option has to be ordered and the external GPS receiver has to be installed within 25 meters of the GPS antenna. If the external GPS option is used, then it will be necessary to install a power and data cable between the external GPS receiver and the recorder. An assigned vendor supplies a custom cable for this application or you can use a different cable using the appropriate guidelines as published in their operations manual.

\section{A.4 SUMMARY OF DIGITAL RECORDERS}

\section{A.4.1 K-2 Digital Recorder}

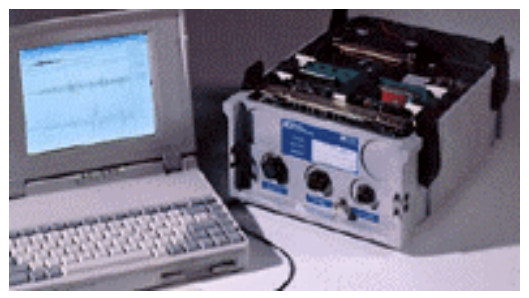

Figure A-4. Modern digital K-2 recording system can download data to a laptop or transfer by modem or other communications media.

One of the state-of-the-art digital recording systems is the K-2 recorder that has sensor interface, choice of sampling rates (20-250 sps), multi-recording modes, communication 
interfaces (RS232cable and/or modem) and recording as a data-logger with storage on local flash card hard disks of any size. These capabilities facilitate recording recording with shortperiod and broadband seismometers. The data can be transferred by site visit to manually retrieve the data or by dialing up the system. The system also works as a digitizer and can communicate via radio, telephone or satellites links, sending a serial data stream to another recording media such as a desktop computer.

The sensor interface has a pre-amplifier board that can take input of 40 volts peak-to-peak (+/- 10 volts differential) to provide a direct connection for broadband seismometers. Shortperiod seismometers can also be used with gain of X1, X3, X10, X30 or X100. The units can also be modified by installation of damping resistors.

For most structural instrumentation applications, high-frequency transducers such as accelerometers and velocity transducers are used. These transducers in general require high sampling rates (e.g. 100-200sps). However, the K-2 units are capable of recording with broadband seismometers at low sampling rates also. Data recorded by a K-2 unit can be retrieved by several methods:

1. Remove the flash card or hard disk and place it in a PC card slot on the analysis computer. Analysis software can then open the files as it would any other program file. By this way, data transfer is not necessary.

2. Direct connection with the RS-232C cable. Data transfer or interrogation can be accomplished over the serial port without having to first stop data acquisition. Finally, the data can be transferred to a remote-site computer via telephone, radio or satellite.

3. Using an internal high-speed telephone (14.4 KB, $28.8 \mathrm{~KB}$, or $56 \mathrm{~KB})$, cellular or ISDN modem installed on the second PC card slot and runs off the same power supply as the K2 system.

4. Using an external telephone (traditional or cellular) or radio modem connected to the RS-232C port. Usually for radio connection, spread spectrum radio modems (902-928 $\mathrm{MHz}$ ) are used.

5. Specific software can be used to automatically transfer from a network of K2s to a PC.

Data from $\mathrm{K} 2$ can also be transferred continuously and in real-time to a central data acquisition system using radio, telephone or satellite communication links.

Dynamic range of K2 series is greater than $114 \mathrm{~dB}$. The data acquisition can be accomplished with 24-bit DSP (digital signal processing). 


\section{A.4.2 Mt. Whitney Recording System}

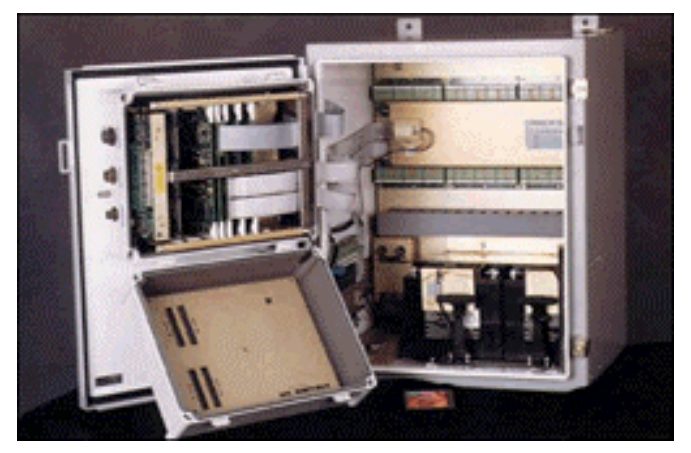

Figure A-5. Mt. Whitney - an up to 18-channel digital recording system specifically used for structural monitoring

Mostly used for structural monitoring purposes, the Mt. Whitney is an 18-channel central recording (requiring only one master board), high dynamic range (>110dB) accelerograph system. The 18 channels of acceleration data are acquired in a single file at 19 bits of resolution at $200 \mathrm{sps}$.

As with K-2, the data is stored on flash card type hard disk and is equipped with a GPS receiver for synchronization to absolute time and an internal PCMCIA modem for remote alerting and data transfer. It has remote alerting capability for both event and alarm incidence. 